\title{
Therapeutic Management of a Patient with Necrotizing Fasciitis Resulting in Quadrilateral Amputation and Critical Illness Myopathy in the Intensive Care Setting: A Case Report.
}

\author{
Mallory A. Kargela \\ Midwestern University, mkarge1@midwestern.edu \\ Annette J. Siebens \\ Mayo Clinic Hospital, asieb68@gmail.com
}

Follow this and additional works at: https://nsuworks.nova.edu/ijahsp

Part of the Occupational Therapy Commons, Orthotics and Prosthetics Commons, Other Rehabilitation and Therapy Commons, Physical Therapy Commons, and the Physiotherapy Commons

\section{Recommended Citation}

Kargela MA, Siebens AJ. Therapeutic Management of a Patient with Necrotizing Fasciitis Resulting in Quadrilateral Amputation and Critical Illness Myopathy in the Intensive Care Setting: A Case Report.. The Internet Journal of Allied Health Sciences and Practice. 2021 Jan 01;19(1), Article 18.

This Case Study is brought to you for free and open access by the College of Health Care Sciences at NSUWorks. It has been accepted for inclusion in Internet Journal of Allied Health Sciences and Practice by an authorized editor of NSUWorks. For more information, please contact nsuworks@nova.edu. 


\title{
Therapeutic Management of a Patient with Necrotizing Fasciitis Resulting in Quadrilateral Amputation and Critical Illness Myopathy in the Intensive Care Setting: A Case Report.
}

\begin{abstract}
Purpose: The purpose of this case is to illustrate the best available evidence to provide early therapeutic intervention for a critically ill patient presenting with cardiovascular and pulmonary complications due to multi-system compromise. Case Description: A 19-year-old male was admitted to the hospital with the diagnosis of necrotizing fasciitis and necrotizing pneumonia. He experienced numerous additional medical complications ultimately leading to tracheostomy, delirium, critical illness myopathy, and quadrilateral amputation secondary to necrotizing fasciitis and critical limb ischemia following prolonged veno-venous extracorporeal membrane oxygenation (VV-ECMO). Outcomes: Patient was discharged to an outside rehabilitation hospital after 103 days in the acute setting (56 days in the ICU) and was able to tolerate 40 minutes sitting edge of bed with supervision, perform bed mobility with supervision, and propel a standard wheelchair up to 50 feet independently. At 10 months' post-discharge from the acute setting, the patient was ambulating independently up to 150 feet without assistive device using bilateral lower extremity prosthetics, able to propel a lightweight wheelchair community distances, independent in all transfers, and returned to school and work. Discussion: These findings suggest that clinicians may want to consider examining and combining the best available evidence of multiple medical conditions to provide a wellrounded therapeutic approach including but not limited to, close monitoring of vitals and early mobilization, to managing complex patients in the intensive care setting.
\end{abstract}

\section{Author Bio(s)}

Mallory A. Kargela, PT, DPT, is an Assistant Professor in the College of Health Sciences at Midwestern University in Glendale, Arizona. She is a licensed physical therapist and practices primarily in the intensive care setting.

Annette J. Siebens, OTR/L, is a licensed occupational therapist at Mayo Clinic Hospital in Phoenix, Arizona. She practices primarily in the intensive care setting.

\section{Acknowledgements}

The authors of this case study would like to thank the patient and his family for the effort and intensity put into his recovery. Additionally, thank you for allowing permission to release photos for the purpose of growing our body of evidence and advancing knowledge of the physical therapy profession. Lastly, the authors would like to thank Mayo Clinic Hospital Arizona, the ICU nurses and medical staff, and Dr. Ayan Sen for the interprofessional collaboration and mentorship throughout the patient's journey to recovery. 


\title{
1IVAHSP \\ The Internet Joumnal of Allied Health Sciences and Practice \\ Dedicated to allied health professional practice and education
}

Vol. 19 No. 1 ISSN 1540-580X

\section{Therapeutic Management of a Patient with Necrotizing Fasciitis Resulting in Quadrilateral Amputation and Critical Illness Myopathy in the Intensive Care Setting: A Case Report.}

\author{
Mallory A. Kargela ${ }^{1}$ \\ Annette J. Siebens ${ }^{2}$ \\ 1. Midwestern University \\ 2. Mayo Clinic Hospital \\ United States
}

\begin{abstract}
Purpose: The purpose of this case is to illustrate the best available evidence to provide early therapeutic intervention for a critically ill patient presenting with cardiovascular and pulmonary complications due to multi-system compromise. Case Description: A 19year-old male was admitted to the hospital with the diagnosis of necrotizing fasciitis and necrotizing pneumonia. He experienced numerous additional medical complications ultimately leading to tracheostomy, delirium, critical illness myopathy, and quadrilateral amputation secondary to necrotizing fasciitis and critical limb ischemia following prolonged veno-venous extracorporeal membrane oxygenation (VV-ECMO). Outcomes: Patient was discharged to an outside rehabilitation hospital after 103 days in the acute setting (56 days in the ICU) and was able to tolerate 40 minutes sitting edge of bed with supervision, perform bed mobility with supervision, and propel a standard wheelchair up to 50 feet independently. At 10 months' post-discharge from the acute setting, the patient was ambulating independently up to 150 feet without assistive device using bilateral lower extremity prosthetics, able to propel a lightweight wheelchair community distances, independent in all transfers, and returned to school and work. Discussion: These findings suggest that clinicians may want to consider examining and combining the best available evidence of multiple medical conditions to provide a well-rounded therapeutic approach including but not limited to, close monitoring of vitals and early mobilization, to managing complex patients in the intensive care setting.
\end{abstract}

Keywords: critical illness myopathy, necrotizing fasciitis, physical therapy, necrotizing pneumonia, intensive care setting 


\section{INTRODUCTION}

There is a very limited body of evidence to guide physical therapists' strategy in those with multiple and complex conditions within intensive care unit (ICU) settings. ${ }^{1}$ Case reports within healthcare settings have been proven to be beneficial for a variety of reasons, including the presentation of rare diseases. ${ }^{2}$ This particular case report highlights the importance and clinical significance of individualized and personalized physical therapy intervention for a patient with the rare diagnosis of necrotizing fasciitis complicated by necrotizing pneumonia. ${ }^{3}$ Furthermore, this case report offers a structure for case-based learning within intensive care settings for a patient experiencing compromise of the cardiovascular and pulmonary systems and may facilitate improvements in the delivery of physical and occupational therapy interventions for patients with a similar presentation.

\section{CASE REPORT}

A 19-year-old, right-handed male was admitted to the hospital and referred for physical therapy consult with the primary medical diagnoses of necrotizing pneumonia and necrotizing fasciitis. Prior to onset of symptoms, the patient had an unremarkable past medical history and was independent in all functional activities. Patient resided with roommates while attending college but lived with family when in Arizona. At time of physical therapy initial evaluation, the patient had been decannulated from VV-ECMO, and undergone right below knee amputation, left above knee amputation, left transmetacarpal amputation, and right thumb interphalangeal and digits 2-5 metacarpal amputation.

Prior to physical therapy evaluation, the patient had experienced many medical setbacks and complications throughout the 2 weeks required to stabilize his condition. In addition to quadrilateral amputations, he experienced sepsis, multiple blood transfusions, necrotizing pneumonia requiring mechanical ventilation with subsequent delirium and critical illness myopathy. During initial physical examination, the patient was lethargic secondary to a ketamine drip utilized for pain management but able to participate in therapy. His Functional Independence Measure (FIM) score was a 25 overall, indicating low functional independence. His Functional Status Score for Intensive Care Unit Settings (FSS-ICU) was 1, as he was limited in ability to participate in functional movements at the time of evaluation due to sedatives, pain medication, and reported pain and anxiety surrounding fear of movement. Refer to Table 1 for a complete list of the patient's medications at time of physical therapy evaluation.

Table 1: Medication List

\begin{tabular}{|c|c|}
\hline Medication & Dosage \\
\hline \multicolumn{2}{|l|}{ Scheduled Medications } \\
\hline Nitroglycerin & $0.4 \%$ topical ointment, BID \\
\hline Zinc sulfate & $5 \mathrm{~mL}, \mathrm{TID}$ \\
\hline Protonix & $10 \mathrm{~mL}$, daily \\
\hline Solu-cortef & $0.5 \mathrm{~mL}, \mathrm{Q} 6 \mathrm{H}$ \\
\hline Gabapentin & $6 \mathrm{~mL}$, daily \\
\hline Cancidas & $50 \mathrm{mg}, \mathrm{Q} 24 \mathrm{H}$ interval \\
\hline Cleocin & $50 \mathrm{~mL}, \mathrm{Q} 8 \mathrm{H}$ \\
\hline Bacitracin & Topical ointment, TID \\
\hline Vitamin B1 & $2 \mathrm{~mL}$, daily \\
\hline Ergocalciferol & $6.25 \mathrm{~mL}, \mathrm{Q} 7$ days \\
\hline Vancocin & $200 \mathrm{~mL}$, daily \\
\hline \multicolumn{2}{|l|}{ Continuous Drip Medications } \\
\hline Fentanyl & $250 \mathrm{~mL}, 10 \mathrm{~mL} /$ hour continuous \\
\hline Dexmedetomidine & $200 \mathrm{mcg}$, continuous \\
\hline Ketamine in sodium chloride solution & $250 \mathrm{~mL}$, continuous \\
\hline \multicolumn{2}{|l|}{ Medications Delivered as Needed } \\
\hline Potassium chloride & $100 \mathrm{~mL}, \mathrm{Q} 1 \mathrm{H}$ \\
\hline Albuminar & $100 \mathrm{~mL}, \mathrm{Q} 1 \mathrm{H}$ \\
\hline Versed & $2 \mathrm{~mL}, \mathrm{Q} 2 \mathrm{H}$ \\
\hline Insulin & 0-7 units, as directed \\
\hline Ketamine & $5 \mathrm{~mL}$, as directed \\
\hline Fentanyl & $1.5 \mathrm{~mL}, \mathrm{Q} 1 \mathrm{H}$ \\
\hline Diasylate & As directed \\
\hline Sodium phosphate & $5 \mathrm{~mL}$, as directed \\
\hline
\end{tabular}


Note: $B I D=$ twice daily, $m L=$ milliliters, $T I D=$ three times daily, $Q x H=$ every $x$ hours

The patient presented with notable deficits across multiple systems. Refer to Table 2 for an overview of the systems review results. The systems review guided the initial selection of tests and measures performed. Using information obtained from the chart review and the patient and family, assessment of cognition, vital signs, subjective pain rating, skin integrity and incision assessments, functional mobility and endurance, muscle strength and range of motion, it was determined that this patient had complex therapeutic deficits. The patient was an excellent candidate for this case study due to the complexity of comorbid conditions and the limited research on therapeutic approach for patients with these medical complexities.

Table 2: Systems Review and Examination Findings

\begin{tabular}{|c|c|}
\hline Systems Review & Initial Evaluation Findings \\
\hline Cardiovascular/pulmonary & $\begin{array}{l}\text { Impaired. Medications were utilized to maintain control of cardiovascular } \\
\text { and pulmonary function. } \\
\text { Vital signs } \\
\text { Heart Rate: } 81 \text { beats per minute (bpm) } \\
\text { Blood Pressure: } 129 / 66 \mathrm{mmHg} \text { (millimeters of mercury) } \\
\text { Respiratory Rate: } 8 \text { breaths per minute } \\
\text { Oxygen Saturation: } 95 \% \text { via tracheostomy collar at FiO2 } 40 \% \text { and } 30 \mathrm{~L}\end{array}$ \\
\hline Integumentary & $\begin{array}{l}\text { Impaired. Surgical incisions were present under wound dressings. Wound } \\
\text { Vac on left lower extremity. }\end{array}$ \\
\hline Musculoskeletal & Impaired. See Table 3. \\
\hline Neuromuscular & $\begin{array}{l}\text { Impaired. Light touch sensation intact at bilateral upper extremities from } \\
\text { shoulder to mid-forearm and bilateral lower extremities from left groin to mid- } \\
\text { thigh and right groin to mid-shin. Unable to test distally secondary to wound } \\
\text { dressings. }\end{array}$ \\
\hline Genitourinary & $\begin{array}{l}\text { Impaired. Continuous renal replacement therapy (CRRT) utilized to maintain } \\
\text { kidney function. }\end{array}$ \\
\hline Gastrointestinal & $\begin{array}{l}\text { Impaired. Parenteral nutrition and left colostomy bag were utilized to } \\
\text { maintain adequate nutrition and excretion. }\end{array}$ \\
\hline $\begin{array}{l}\text { Cognition, Communication, } \\
\text { Affect, Learning Style }\end{array}$ & $\begin{array}{l}\text { Impaired. The patient was oriented to person, place, and time however } \\
\text { therapists were unable to determine if he was oriented to the situation. His } \\
\text { communication was limited to head nodding and mouthing yes/no } \\
\text { responses. The patient's learning style was unable to be assessed. }\end{array}$ \\
\hline Tests and Measures & Initial Evaluation Findings \\
\hline 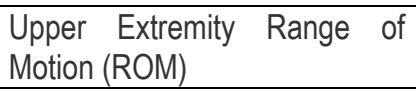 & $\begin{array}{l}\text { Intact. Patient demonstrates full ROM for passive and active assist shoulder } \\
\text { and elbow motions. Motions at the wrist/hands were not assessed. }\end{array}$ \\
\hline $\begin{array}{l}\text { Lower Extremity Passive } \\
\text { Range of Motion (PROM) }\end{array}$ & $\begin{array}{l}\text { Left lower extremity } \\
-\quad \text { Hip extension to neutral, limited by pain (sidelying) } \\
\text { - Hip abduction to } 5 \text { degrees (sidelying) } \\
\text { Right lower extremity } \\
\text { - Hip extension to }-5 \text { degrees, limited by pain (sidelying) } \\
\text { - Hip abduction to neutral, limited by pain (sidelying) } \\
\text { Knee extension to - } 10 \text { degrees (supine) }\end{array}$ \\
\hline $\begin{array}{l}\text { Lower Extremity Active Assist } \\
\text { Range of Motion (AAROM) }\end{array}$ & 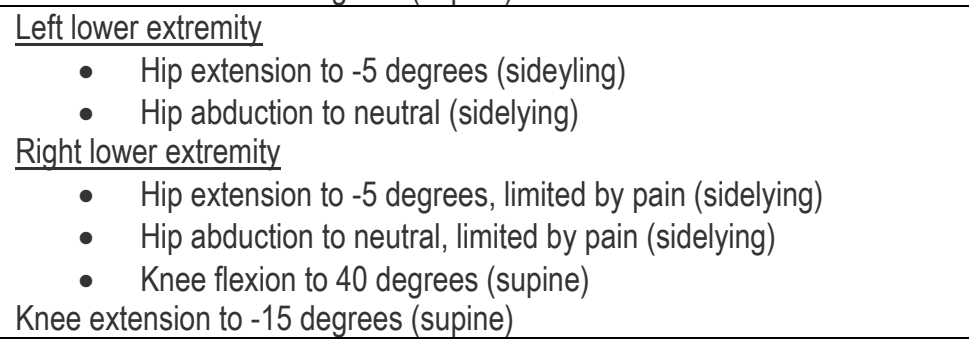 \\
\hline
\end{tabular}




\begin{tabular}{|c|c|}
\hline $\begin{array}{lcl}\text { Upper } & \text { Extremity } & \text { Manual } \\
\text { Muscle Testing (MMT) }\end{array}$ & $\begin{array}{ll}\text { Left upper extremity } \\
\text { - } & \text { Shoulder flexion: } 1 / 5 \\
\text { - } & \text { Shoulder extension: } 1 / 5 \\
\text { - } & \text { Shoulder abduction: } 1 / 5 \\
\text { - } & \text { Elbow flexion: } 2 / 5 \\
\text { - } & \text { Elbow extension: } 2 / 5 \\
\text { - } & \text { Wrist/hand not assessed secondary to recent amputation at } \\
& \text { manual contact points. } \\
\text { Right upper extremity } \\
\text { - } & \text { Shoulder flexion: } 1 / 5 \\
\text { - } & \text { Shoulder extension: } 1 / 5 \\
\text { - } & \text { Shoulder abduction: } 1 / 5 \\
\text { - } & \text { Shoulder adduction: } 1 / 5 \\
\text { - } & \text { Elbow flexion: } 3-/ 5 \\
\text { Wrist/hand not assessed secondary to recent amputation at manual contact } \\
\text { points. }\end{array}$ \\
\hline Lower Extremity MMT & $\begin{array}{l}\text { Left lower extremity } \\
\qquad \quad \text { Left hip extension } 0 / 5 \text { (supine) } \\
\text { - Left hip abduction to } 1 / 5 \text { (supine) } \\
\text { Right lower extremity } \\
\text { - } \quad \text { Right hip extension } 1 / 5 \text { (supine) } \\
\text { - Right hip abduction } 1 / 5 \text { (supine) } \\
\text { Right knee flexion/extension not assessed secondary to recent } \\
\text { amputation at manual contact points. } \\
\text { Patient was able to move against gravity into flexion and extension, will } \\
\text { assess in future for formal MMT }\end{array}$ \\
\hline Cough Assessment & $\begin{array}{l}\text { Patient was able to produce a weak, ineffective cough with head of bed at } \\
45 \text { degrees. He had decreased middle and lower chest wall expansion and } \\
\text { required tracheal suction to clear secretions. }\end{array}$ \\
\hline Sputum Analysis & $\begin{array}{l}\text { Sputum was thick, milky white/pale green which was consistent for } \\
\text { presentation of consolidation of the left posterior upper lobe. }\end{array}$ \\
\hline Functional Mobility: Rolling & $\begin{array}{l}\text { Dependent: required maximum assistance of } 2 \text { therapists in either direction. } \\
\text { Physiologic response } \\
\text { Patients heart rate increased to } 98 \mathrm{bpm} \text {, and returned to } 83 \mathrm{bpm} \text { within } 30 \\
\text { seconds of return to head of bed at } 45 \text { degrees }\end{array}$ \\
\hline $\begin{array}{l}\text { Functional Mobility: Supine to } \\
\text { Sit Transfer }\end{array}$ & $\begin{array}{l}\text { Unable to attempt secondary to anxiety expressed by patient regarding early } \\
\text { mobility }\end{array}$ \\
\hline $\begin{array}{l}\text { Functional Mobility: Wheelchair } \\
\text { Propulsion }\end{array}$ & $\begin{array}{l}\text { Unable to attempt secondary to positional restrictions set by plastic surgery } \\
\text { team }\end{array}$ \\
\hline Numeric Pain Rating Scale & $3 / 10$ at quadrilateral surgical sites \\
\hline AM-PAC 6-clicks^ & $\begin{array}{l}\text { 8/24 (basic mobility domain), 6/24 (daily activity domain) } \\
\text { (indicates high level of physical assistance needed) }\end{array}$ \\
\hline FSS-ICU* & 1/35 (indicates lower physical functioning) \\
\hline $\mathrm{FIM}^{\#}$ & $\begin{array}{l}12 \text { cognition/ADLs, } 13 \text { motor } \\
\text { Total } 25 / 126 \text { (indicates low level of }\end{array}$ \\
\hline
\end{tabular}

As the examination progressed, tests and measures were selected and utilized to determine the patient's overall functional ability and cardiovascular endurance to provide an appropriate discharge recommendation for when he was determined to be ready to progress to the next level of care. The results of these tests are provided in Table 3. The primary problem at the time of initial evaluation was a significant decline in his baseline function, and therefore a battery of function-based outcome measures was selected to track progress. The Activity Measure for Post-Acute Care Inpatient Short Form (AM-PAC 6-clicks) was utilized as it 
was a standardized measure utilized in the medical facility, but also has high test-retest and interrater reliability as well as internal

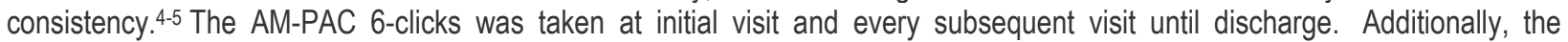
Functional Status Score for the ICU (FSS-ICU) and Functional Independence Measure (FIM) were both utilized at time of initial evaluation to aide in decision-making related to overall functional performance within the acute care setting. The FSS-ICU has good internal consistency and is considered a valid and responsive measure of physical function for patients within the ICU setting, specifically. ${ }^{6}$ The FIM was selected, as the therapists were not certain of the patient's cognitive deficits from prolonged VV-ECMO and the tool offers both motor and cognitive scores. Also, the patient's age and expressed motivation to recover made him a strong candidate to consider for acute inpatient rehabilitation where the FIM is more widely used. The FIM has excellent interrater consistency among neurological disorders. ${ }^{7}$ The FSS-ICU and FIM were taken at initial visit and at ICU discharge date. The patient's scoring on outcome measures at initial visit and ICU discharge are shown in Table 3.

Table 3: Functional Outcome Measures at Evaluation and Discharge

\begin{tabular}{|c|c|c|}
\hline Outcome Measure & ICU Evaluation Score & ICU Discharge Score \\
\hline $\begin{array}{l}\text { Functional Status Score for the ICU } \\
\text { (FSS-ICU)* }\end{array}$ & 1 & 10 \\
\hline $\begin{array}{l}\text { Functional Independent Measure } \\
(\text { FIM)\# }\end{array}$ & $\begin{array}{l}13 \text { motor } \\
12 \text { cognition } \\
25 \text { overall } \\
\end{array}$ & $\begin{array}{l}18 \text { motor } \\
28 \text { cognition } \\
46 \text { overall } \\
\end{array}$ \\
\hline $\begin{array}{l}\text { Activity Measure for Post-Acute Care } \\
\text { (AM-PAC) }-6 \text { Clicks }^{\wedge}\end{array}$ & $\begin{array}{l}8 \text { mobility } \\
6 \text { activity }\end{array}$ & $\begin{array}{l}12 \text { mobility } \\
17 \text { activity }\end{array}$ \\
\hline
\end{tabular}

This patient's history and examination findings were consistent with the medical diagnosis of necrotizing pneumonia with residual consolidation of the left upper lobe, as well as quadrilateral amputations. In addition, prolonged time on mechanical ventilation, VV-ECMO, and CRRT contributed to delirium and critical illness myopathy, which in combination with conditions previously mentioned, resulted in significant functional decline from baseline. The patient presented with impaired muscle performance; range of motion; gait, locomotion, and balance; and ventilation/gas exchange. He was functionally limited in self-care, home management, and work, community, and leisure activities. At time of evaluation, he was on mechanical ventilation. The primary physical therapy diagnosis was consistent with impaired ventilation and respiration/gas exchange associated with respiratory failure and impaired motor function, muscle performance, range of motion, gait, locomotion, and balance associated with amputation. Additionally, based on his exam, the additional deficits related to impaired ventilation, respiration/gas exchange, and aerobic functional capacity associated with airway clearance dysfunction and deconditioning.

At the time of initial evaluation, the patient had experienced several medical setbacks and complex conditions that contributed to the therapists anticipating a prolonged course of care. The patient's predicted level of functional improvement was not known, as he had experienced several medical setbacks during his course of care. It is well documented that those who are experience prolonged mechanical ventilation, VV-ECMO, and other life-saving interventions in the ICU settings also experience long-term effects such as critical illness myopathy and post-intensive care syndrome (PICS). ${ }^{8-9}$ The therapists considered and anticipated the unfavorable prognostic indicators related to prolonged ICU stays, such as emotional and psychological effects, and collaborated with other medical professionals on a holistic plan of care. Both the patient and the patient's family had experienced significant trauma leading up to the therapeutic evaluation, and expressed anxiety and apprehension surrounding the therapeutic process, mostly related to early mobility. This led the therapists to advocate for a psychology consult and other mental health resources for the patient and his family.

These additional resources included recreational therapy, music therapy, and increased outdoor privileges (as medically able), which did provide a positive experience for the patient and family. Despite the many adverse events that patient encountered during this length of stay, he had a strong social support system willing to participate in the therapeutic process. He expressed strong motivation and participated actively in the intended outcomes of therapy. Both the patient's support system and motivation were considered favorable prognostic indicators for functional improvements. Based on mutually agreed upon goals, the patient was seen daily over the course of 56 days in the ICU in order to produce measurable improvements in aerobic capacity/endurance, functional status in activities of daily living (ADLs), locomotion/balance, muscle performance, ROM, airway clearance, functional cough, and physical and psychological state. To achieve these outcomes, the therapists used a targeted, evidence-based plan of care that focused on patient and family education and instruction, therapeutic exercise, functional training in self-care, functional training in locomotion, prescription, fabrication, and application of orthotic equipment, and airway clearance techniques. 
Therapeutic interventions were implemented to target the patient's impairments within the cardiovascular/pulmonary, musculoskeletal, neuromuscular, and cognition/communication/affect systems. Impairments noted within the integumentary system were managed by the nursing staff and plastic surgeon, however maintenance of surgical site integrity was targeted within physical therapy through patient and family education within each visit. Evidence-based therapeutic interventions and delivery method can be found in the Appendix.

Early in the patient's course of care, postural drainage was utilized to provide airway clearance and secretion removal. ${ }^{10}$ The most tolerated and successful position for the patient was in right side lying with head of bed elevated to 30 degrees. This position targeted the left posterior segment of the upper lobe. Vibration and percussion were not utilized early in the therapeutic intervention, as patient had expressed anxiety. However, the therapists were able to provide both vibration and percussive techniques coupled with postural drainage as the course of care progressed and the patient found success in airway clearance. Continued patient and family education and instruction was provided for effective cough strategy as well as use of upright positioning for effective airway clearance.

Additionally, the use of upper extremity (UE) adapted cycling and strengthening were utilized to provide both cardiovascular training and range of motion. Vitals were continuously monitored, and the use of Borg Rate of Perceived Exertion (RPE) was utilized so that the cardiovascular system was not overwhelmed in the acute phase of recovery. Sommers et al ${ }^{11}$ described the benefits of using UE cycling with interval training sessions when discussing the importance of early physical therapy for patients within the ICU settings. Strengthening protocols with use of TheraBand as well as proprioceptive neuromuscular facilitation (PNF) are well documented in the literature for patients who have experienced an ICU stay and sepsis. ${ }^{12-13}$ Graded motor imagery and relaxation techniques were utilized to assist in phantom pain management and anxiety during therapeutic sessions. ${ }^{14}$ The patient experienced a positive outcome with these techniques and found them to be helpful in other aspects of his medical stay beyond therapy sessions (debridement, dressing changes, etc.). Bed mobility and transfer training were implemented to enhance the patient's functional independence and increase the likelihood of meeting acute inpatient rehabilitation requirements at time of hospital discharge. The value and benefit of functional mobility retraining in the ICU is well documented for a variety of conditions, including prolonged mechanical ventilation. ${ }^{12,15-17}$ The patient had expressed early on in the therapeutic process that his main goal was to return to an independent state, and therefore, coupled with the clinical judgement of the therapists and recommendation in the literature, functional mobility retraining was the main focus of hospital-based physical therapy.3,15-17 Lastly, the therapists were aware of the patient and family members likelihood of experiencing anxiety, stress, and apprehension given the patient's trauma and long length of stay in an ICU. They followed the recommendations of Falgares et al ${ }^{18}$ that guided them to providing resources outside of therapy time to manage stress and anxiety.

Overall, the patient remained adherent and highly motivated. Initially in the ICU, the patient received co-interventions with physical and occupational therapies due to his significant decline in cardiovascular endurance and lethargy. However, over time, he was able to participate in multiple therapeutic sessions daily without the need for co-interventions. Progression of all interventions were based on the patient's performance and as part of a collaborative decision-making process among the therapeutic team.

\section{OUTCOMES}

Over the course of 79 physical therapy visits and 103 total days in the acute setting (56 of which were in the ICU), the patient made meaningful improvements in functional mobility and on all functional outcome measures utilized. The patient transitioned from total dependence for all functional movement to supervision only using the bed rail for rolling, supervised sitting at edge of bed for ADLs, and propelling a wheelchair independently up to 50 feet. At ICU discharge, the patient demonstrated meaningful change on the FSS-ICU, and at discharge from the acute care hospital demonstrated meaningful change on the FIM and AM-PAC 6-clicks. Minimal detectable change for the FSS-ICU, FIM, and AM-PAC 6-clicks are 2-5, 22, and 4.28 (motor)/3.70 (activity), respectively (see Table 3). At 10 months' post-discharge from the acute setting, the patient was ambulating up to 150 feet without assistive device using bilateral lower extremity prosthetics, able to propel a lightweight wheelchair community distances, was independent in all transfers, and had returned to school and work.

Although the patient was considered medically stable throughout most of his inpatient episode of care, he did experience several medical setbacks during this time, including repeat surgical debridement and removal of necrotic tissue of bilateral lower extremities, difficulty controlling pain and bleeding post-debridement, and depression. After each debridement procedure, the patient was placed on a medical hold per the surgeon for 3-5 days, after which therapy would re-assess and continue per the reestablished plan of care. The course of care was further delayed due to the influence of intermittent ketamine use for debridement procedures contributing to delirium and lethargy. The delirious states occurred on days 30-40 and manifested in hallucinations, anxiety, and paranoia. The therapists managed the delirium episode with continued structure therapy, descriptive and succinct 
explanation of therapy, and focus on patient obtaining good quality sleep during the nighttime hours. ${ }^{19}$ Additionally, the patient was able to successfully wean from strong sedatives during this time which contributed to his return to cognitive baseline by day 40 of hospital stay. Despite the temporary shift in cognitive function during the delirious state, it did not seem to affect the physical therapy plan of care, as the patient continued to progress toward all therapeutic goals.

Despite the stated medical complications and interruptions to therapy, the patient remained highly motivated and participatory in his care. Interventions were well tolerated by the patient and assessed in the ICU by the response of heart rate, blood pressure, and oxygen saturation. Adherence from the patient was rarely considered a negative factor in his progress; however, the therapists did intervene with the patient's family early on. The patient's parents' anxiety and apprehension toward therapeutic progression was apparent throughout the patient's course of care. In response, the therapist's provided each family member a role in the therapeutic process. The use of family members as a participant in a loved one's care is well-supported in the evidence and the patient's mother reported this intervention aided in reducing her anxiety toward early mobility. ${ }^{20}$ Additionally, the therapists' worked with the patient directly to establish daily therapeutic goals that were meaningful to him and his recovery. Utilizing this strategy worked to provide the patient some aspect of control in their course of care, improving his adherence to the therapeutic plan.

\section{DISCUSSION}

This case study highlights the application of evidence-based rehabilitation to a patient with multiple diagnoses. With limited resources available to guide the clinicians in practice, they were able to combine interventions from numerous resources to provide evidence-based interventions. Research is prevalent when considering mechanically ventilated patients and those carrying a diagnosis of acute respiratory distress syndrome (ARDS). ${ }^{21-23}$ However, the patient in this case had the medical complexities of quadrilateral amputation as well as delirium and critical illness myopathy $(\mathrm{CIM})$ compounding the total effects of his time in the intensive care unit. The evidence supports intervening early and often for those who suffer with delirium and CIM within the ICU settings. ${ }^{24-26}$ Unfortunately, there remains a lack of evidence-based resources surrounding therapeutic intervention when delirium and $\mathrm{CIM}$ are combined with additional complex medical diagnoses. ${ }^{27}$

\section{Limitations}

One major limitation of this case study is the high degree of complexity of the medical conditions presented made it difficult to find research describing best practice to guide the therapeutic process. Another limitation to the study is the number and quality of evidence available for the patient's specific comorbid conditions as related to physical therapy. No publications were found specifically discussing the therapeutic role in necrotizing fasciitis or necrotizing pneumonia. Due to the limitations in evidence for this patient's presentation, the therapists utilized the best available evidence to formulate a comprehensive intervention plan. This approach involved searching for high-level evidence (randomized controlled trials and systematic reviews) that focused on the patient's primary diagnoses of ARDS and quadrilateral amputations, followed by secondary diagnoses of critical illness myopathy, prolonged mechanical ventilation, and delirium. This yielded many recent publications that fit the patient diagnoses, but also included the use of one case study ${ }^{28}$ and several publications over 10 years old. One randomized controlled trial found that intensive physical therapy did not improve long-term physical functional performance compared with a standard program for mechanically intubated patients. ${ }^{29}$ Despite these findings, the therapists were able to find many other publications citing the value and benefits of early and aggressive therapies for patients who are in the ICU and mechanically ventilated. ${ }^{13-14,19,23-27}$

\section{Strengths}

Although this case had its limitations, one major strength is the functional outcome demonstrated by the patient during his length of stay and post-discharge. The patient was discharged to an outside rehabilitation hospital after 103 days in the acute setting (56 days in the ICU) and was able to sit edge of bed for self-care/ADLs and perform bed mobility with supervision and propel a standard wheelchair independently. At 10 months' post-discharge from the acute setting, the patient was ambulating up to 150 feet without assistive device using bilateral lower extremity prosthetics, able to propel a lightweight wheelchair community distances, independent in all transfers, and returned to meaningful recreation, specifically yoga and weight training. At the time of this manuscript, the patient is living independently, attending school full-time, participates in a part-time job, and volunteers for a nonprofit, all with the accommodation of a trained therapy dog.

\section{CONCLUSION}

This case study highlights the difficulty clinicians can encounter when searching for evidence-based guidelines regarding multiple complex comorbid conditions in a specific patient population. Therefore, it is necessary to consider that if the therapeutic approach of this case solely focused on typical post-amputation intervention, ARDS, or early mobility without the consideration of all contributing medical issues of this patient (necrotizing pneumonia, hemodynamic instability secondary to medications, and 
psychological impact, for example), the functional outcome may have been less favorable. Focusing on only one aspect of this patient's medical course would have likely neglected other areas that required aggressive intervention.

For example, had the therapists neglected the use of airway clearance techniques early on, the patient may have had a longer wean time from the mechanical ventilator, and poorer outcomes and longer length of stay. ${ }^{21}$ The use of postural drainage positioning was highly effective in assisting in airway clearance early on the therapeutic plan; however, the research supporting its use was typically over 10 years old and often times considered outdated. Currently, there are emerging studies highlighting the therapeutic benefits of positioning in those suffering the negative respiratory effects of coronarvirus disease (COVID-19). Also, if the therapeutic focus was solely on early mobility without considering the need for post-amputation specific interventions, the patient may not have attained enough range of motion and strength to be ambulatory with prostheses. Additionally, the patient was on several medications that had significant impact on multiple systems creating hemodynamic instability, with ketamine being the primary influence.

Ketamine is known to increase blood pressure, heart rate and respiratory rate as well as induce hallucinations ${ }^{30}$ and therefore the therapists had to provide continuous and thorough vital monitoring throughout the therapy sessions to ensure that the patient maintained appropriate hemodynamic shifts before, during, and after activity. These findings suggest that clinicians must continually examine and combine the best available evidence of multiple medical conditions to provide a comprehensive therapeutic approach to managing complex patients in the intensive care setting.

Last, considering the psychological impact of a prolonged ICU stay on patients and their family members is critical to a holistic approach to care. An interprofessional relationship including access to psychology professionals, including neuropsychologists within the ICU setting would have a lasting impact on the amount and quality of care the patient receives. With these considerations in place, patients and their families would benefit from high level, interprofessional, and evidence-based care within the ICU and acute care settings.

\section{References}

1. Kimble SL. Acute Inpatient Rehabilitation Interventions and Outcomes for a Person With Quadrilateral Amputation. Physical Therapy. 2016;97(2):161-166. doi:10.2522/ptj.20160044

2. Gagnier JJ, Kienle G, Altman DG, et al. The CARE Guidelines: Consensus-based Clinical Case Reporting Guideline Development. Glob Adv Health Med. 2013;2(5):38-43. doi:10.7453/gahmj.2013.008 PMID: 24416692

3. Khamnuan P, Chongruksut W, Jearwattanakanok K, Patumanond J, Tantraworasin A. Necrotizing fasciitis: epidemiology and clinical predictors for amputation. Int J Gen Med. 2015;8:195-202. Published 2015 May 14. doi:10.2147/IJGM.S82999 PMID: 25999758

4. Jette DU, Stilphen M, Ranganathan VK, Passek S, Frost FS, Jette AM. Interrater Reliability of AM-PAC "6-Clicks" Basic Mobility and Daily Activity Short Forms. Phys Ther. 2015;95(5):758-766. doi:10.2522/ptj.20140174 PMID: 25504489

5. Jette DU, Stilphen M, Ranganathan VK, Passek SD, Frost FS, Jette AM. Validity of the AM-PAC "6-Clicks" inpatient daily activity and basic mobility short forms. Phys Ther. 2014;94(3):379-391. doi:10.2522/ptj.20130199 PMID: 24231229

6. Huang M, Chan KS, Zanni JM, et al. Functional Status Score for the ICU: An International Clinimetric Analysis of Validity, Responsiveness, and Minimal Important Difference. Crit Care Med. 2016;44(12):e1155-e1164. doi:10.1097/CCM.0000000000001949 PMID: 27488220

7. Hobart JC, Lamping DL, Freeman JA, et al. Evidence-based measurement: which disability scale for neurologic rehabilitation?. Neurology. 2001;57(4):639-644. doi:10.1212/wnl.57.4.639 PMID: 11524472

8. Needham DM, Davidson J, Cohen $\mathrm{H}$, et al. Improving long-term outcomes after discharge from intensive care unit: report from a stakeholders' conference. Crit Care Med. 2012;40(2):502-509. doi:10.1097/CCM.0b013e318232da75 PMID: 21946660

9. Griffiths J, Hatch RA, Bishop J, et al. An exploration of social and economic outcome and associated health-related quality of life after critical illness in general intensive care unit survivors: a 12-month follow-up study. Crit Care. 2013;17(3):R100. Published 2013 May 28. doi:10.1186/cc12745 PMID: 23714692

10. George RB, Light RW, Matthay MA, Matthay RA. Chest Medicine: Essentials of Pulmonary and Critical Care Medicine. 5th ed. Philadelphia, PA: LWW; 2006. 
11. Sommers J, Engelbert RH, Dettling-Ihnenfeldt D, et al. Physiotherapy in the intensive care unit: an evidence-based, expert driven, practical statement and rehabilitation recommendations. Clin Rehabil. 2015;29(11):1051-1063. doi:10.1177/0269215514567156 PMID: 25681407

12. Green M, Marzano V, Leditschke IA, Mitchell I, Bissett B. Mobilization of intensive care patients: a multidisciplinary practical guide for clinicians. J Multidiscip Healthc. 2016;9:247-256. Published 2016 May 25. doi:10.2147/JMDH.S99811 PMID: 27307746

13. Hickmann CE, Castanares-Zapatero D, Deldicque L, et al. Impact of Very Early Physical Therapy During Septic Shock on Skeletal Muscle: A Randomized Controlled Trial. Crit Care Med. 2018;46(9):1436-1443. doi:10.1097/CCM.0000000000003263 PMID: 29957714

14. Plumbe L, Peters S, Bennett S, Vicenzino B, Coppieters MW. "Mirror Therapy, Graded Motor Imagery and Virtual Illusion for the Management of Chronic Pain." Cochrane Database of Syst Rev. 2013(1):CD010329. doi: 10.1002/14651858.CD010329

15. Pasquina PF, Miller M, Carvalho AJ, et al. Special Considerations for Multiple Limb Amputation. Curr Phys Med Rehabil Rep. 2014;2(4):273-289. doi:10.1007/s40141-014-0067-9 PMID: 25411651

16. Brigham and Women's Hospital Department of Rehabilitation Services. "Physical Therapy Standards of Care and Protocol." Physical Therapy Standards of Care - Brigham and Women's Hospital, 2011. https://www.brighamandwomens.org/patients-and-families/rehabilitation-services/physical-therapy-standards.

17. Needham DM, Davidson J, Cohen $\mathrm{H}$, et al. Improving long-term outcomes after discharge from intensive care unit: report from a stakeholders' conference. Crit Care Med. 2012;40(2):502-509. doi:10.1097/CCM.0b013e318232da75 PMID: 21946660

18. Falgares G, Lo Gioco A, Verrocchio MC, Marchetti D. Anxiety and depression among adult amputees: the role of attachment insecurity, coping strategies and social support. Psychol Health Med. 2019;24(3):281-293. doi:10.1080/13548506.2018.1529324 PMID: 30299156

19. Barr J, Fraser GL, Puntillo K, et al. Clinical practice guidelines for the management of pain, agitation, and delirium in adult patients in the intensive care unit. Crit Care Med. 2013;41(1):263-306. doi:10.1097/CCM.0b013e3182783b72 PMID: 23269131

20. Davidson JE, Powers K, Hedayat KM, et al. Clinical practice guidelines for support of the family in the patient-centered intensive care unit: American College of Critical Care Medicine Task Force 2004-2005. Crit Care Med. 2007;35(2):605622. doi:10.1097/01.CCM.0000254067.14607.EB PMID: 17205007

21. Schweickert WD, Pohlman MC, Pohlman AS, et al. Early physical and occupational therapy in mechanically ventilated, critically ill patients: a randomised controlled trial. Lancet. 2009;373(9678):1874-1882. doi:10.1016/S01406736(09)60658-9 PMID: 19446324

22. Hanekom S, Gosselink R, Dean E, et al. The development of a clinical management algorithm for early physical activity and mobilization of critically ill patients: synthesis of evidence and expert opinion and its translation into practice. Clin Rehabil. 2011;25(9):771-787. PMID: 21504951

23. Morris PE, Griffin L, Berry M, et al. Receiving early mobility during an intensive care unit admission is a predictor of improved outcomes in acute respiratory failure. Am J Med Sci. 2011;341(5):373-377. doi:10.1097/MAJ.0b013e31820ab4f6 PMID: 21358312

24. Banerjee A, Girard TD, Pandharipande P. The complex interplay between delirium, sedation, and early mobility during critical illness: applications in the trauma unit. Curr Opin Anaesthesiol. 2011;24(2):195-201. doi:10.1097/ACO.0b013e3283445382 PMID: 21386669

25. Fan E. Critical illness neuromyopathy and the role of physical therapy and rehabilitation in critically ill patients. Respir Care. 2012;57(6):933-946. doi:10.4187/respcare.01634 PMID: 22663968

26. Nickels MR, Aitken LM, Walsham J, Barnett AG, McPhail SM. Critical Care Cycling Study (CYCLIST) trial protocol: a randomised controlled trial of usual care plus additional in-bed cycling sessions versus usual care in the critically ill. BMJ Open. 2017;7(10):e017393. Published 2017 Oct 22. doi:10.1136/bmjopen-2017-017393 PMID: 29061618

27. Latronico N, Herridge M, Hopkins RO, et al. The ICM research agenda on intensive care unit-acquired weakness. Intensive Care Med. 2017;43(9):1270-1281. doi:10.1007/s00134-017-4757-5 PMID: 28289812

28. Wong WP. Physical therapy for a patient in acute respiratory failure. Phys Ther. 2000;80(7):662-670. PMID: 10869128

29. Moss M, Nordon-Craft A, Malone D, et al. A randomized trial of an intensive physical therapy program for patients with acute respiratory failure. Am J Respir Crit Care Med. 2016;193(10): 1101-1110. doi: 10.1164/rccm.201505-10390C PMID: 26651376 


\section{ACKNOWLEDGEMENTS:}

The author of this case study would like to thank the patient and his family for the effort and intensity put into his recovery. Additionally, thank you for allowing permission to release photos for the purpose of growing our body of evidence and advancing knowledge of the physical therapy profession. A special acknowledgement and thank you to the co-author of the original publication, Annette Siebens, OTR, who brought wisdom and clinical experience that aided in the patient's progress. Lastly, the author would like to thank Mayo Clinic Hospital Arizona, the ICU nurses and medical staff, and Dr. Ayan Sen for the interprofessional collaboration and mentorship throughout the patient's journey to recovery.

\section{Appendix}

\begin{tabular}{|c|c|}
\hline Intervention & Delivery Method \\
\hline \multirow{2}{*}{\begin{tabular}{|l} 
Passive Range of \\
Motion (PROM)
\end{tabular}} & - 5 times/joint, 1 set, once daily ${ }^{11}$ \\
\hline & $\begin{array}{ll}\text { - } & \text { Lying flat to allow passive hip extension }{ }^{11,15-16} \\
\text { - } & \text { Side-lying with assisted hip extension/hip flexor stretching } \\
& 11-12,15-16\end{array}$ \\
\hline $\begin{array}{l}\text { Graded motor imagery, } \\
\text { relaxation }\end{array}$ & $\begin{array}{l}\text { - Hand laterality } \\
\text { - } \quad \text { Breathing and meditation as distraction methods }{ }^{14} \\
\text { - } \quad \text { Visualizing unclenching of phantom fists and ankle range of motion (ROM) at phantom } \\
\text { ankles }^{14}\end{array}$ \\
\hline MotoMed & - Upper extremity (UE) cycling, interval training building to 10 minutes ${ }^{11,13}$ \\
\hline ||Functional Retraining & $\begin{array}{l}\text { - Rolling, supine to sitting, activities of daily living (ADLs) with modifications, prone } \\
\text { positioning, sitting balance }{ }^{12,15-17}\end{array}$ \\
\hline Strengthening & $\begin{array}{l}\text { - Theraband attached to hospital bed, alternating between upper extremity and shoulder } \\
\text { girdle, and lower extremities and hip girdle.12 } \\
\text { - Proprioceptive neuromuscular facilitation (PNF) D1/D2 and lower extremity diagonals with } \\
\text { assistance progressing to against resistance and reversal-holds. }{ }^{13}\end{array}$ \\
\hline $\begin{array}{l}\text { Psychological Coping } \\
\text { Strategies }\end{array}$ & $\begin{array}{ll} & \text { Advocating of outdoor time intervals } \\
\text { - } & \text { Patient participation in goal setting and daily therapeutic schedule }{ }^{18} \\
\text { - } & \text { Recreational and music therapies consult } \\
\end{array}$ \\
\hline \begin{tabular}{|l|} 
Environmental \\
Modifications \\
\end{tabular} & $\begin{array}{l}\text { - Use of built-up handles } \\
\text { - Use of stabilizing, non-slip materials to improve grip }\end{array}$ \\
\hline \begin{tabular}{|l} 
Airway Clearance \\
Techniques
\end{tabular} & $\begin{array}{l}\text { - Active cycle of breathing and huffing techniques provided every } 2 \text { hours (RN, OT, and PT } \\
\text { collaborative intervention) progressed to manual cough assist }{ }^{29} \\
\text { - Instruction of effective cough technique }{ }^{29} \\
\text { - Positioning } \\
\text { - Right side lying with head of bed elevated to } 30 \text { degrees, targeting the left } \\
\text { posterior segment of the upper lobe. } \\
\text { - } \quad 4-10 \text { minutes } 2 \times / \text { daily initially } \\
\text { Vibration and percussion utilized as patient was able to tolerate positioning }{ }^{10} \\
\text { - Seated to alter work of breathing }\end{array}$ \\
\hline
\end{tabular}

